\title{
Fabry Disease Female Proband With Clinical Manifestations Similar to Hypertrophic Cardiomyopathy
}

\author{
Masakazu Teragaki, ${ }^{1}$ MD $\dagger$, Akemi TANAKA,${ }^{2} \mathrm{MD}$, Kaname AKIOKA, ${ }^{1} \mathrm{MD}$, \\ Hoang Thi Ngkoc LAN, ${ }^{2}$ MD, Yasuaki NisHI, ${ }^{1} \mathrm{PhD}$, Tsunekazu YAMANO, ${ }^{2} \mathrm{MD}$, \\ and Junichi YosHIKAWA, ${ }^{1} \mathrm{MD}$
}

\begin{abstract}
SUMMARY
Fabry's disease is an X-linked inborn error of glycosphingolipid catabolism, resulting from a deficiency in $\alpha$-galactosidase A ( $\alpha$-Gal A). A 56-year-old Japanese woman was at first suspected of having hypertrophic cardiomyopathy. The patient and her son had $\alpha$-Gal A activity in leukocytes that was remarkably below the limit of controls. DNA analysis of the $\alpha$-Gal A gene revealed a novel missense mutation at codon 19 in exon 1, resulting in leucine-to-proline substitution. As a result she was confirmed as a classic Fabry heterozygote. Recent advances in enzyme replacement therapy can reverse the storage of glycosphingolipids in Fabry's disease. Thus, in patients with cardiac hypertrophy, it is important to differentiate Fabry's disease from other causes of hypertrophy. Therefore, it is necessary to measure $\alpha$-Gal A activity in all suspected cases and to analyze genetic abnormalities in heterozygotes. (Jpn Heart J 2004; 45: 685-689)
\end{abstract}

Key words: Fabry's disease, Hypertrophic cardiomyopathy, Missense mutation

FABRY'S disease is an X-linked inborn disorder caused by deficient activity of the lysosomal hydrolase alpha-galactosidase A (EC 3.2.1.22; $\alpha$-Gal A) ${ }^{.1)}$ In normal individuals, this enzyme catalyses the hydrolysis of the $\alpha$-galactosidic linkage at the nonreducing glycosphingolipid terminals. Loss of this activity results in the intralysosomal deposition of neutral glycosphingolipids with terminal $\alpha$ linked moieties primarily in the plasma and vascular endothelium, leading to angiokeratoma, acroparesthesias, and vascular disease of the heart, kidneys, and brain. In the clinically severe classic form, the onset of disease manifestations usually occurs in childhood or adolescence, while an atypical variant with resid-

From the Departments of ${ }^{1}$ Internal Medicine and Cardiology, and ${ }^{2}$ Pediatrics, Osaka City University Medical School, Osaka, Japan.

(†Present address: Department of Internal Medicine and Cardiology, Wakakusa Daiichi Hospital.)

Address for correspondence: Masakazu Teragaki, MD, Department of Internal Medicine and Cardiology, Osaka City University Medical School, 1-4-3, Asahimachi, Abeno-ku, Osaka 545-8585, Japan.

(†Present address: 1-6, Wakakusa-cho, Higashi-osaka 579-8056, Japan.)

Received for publication November 4, 2003.

Revised and accepted January 9, 2004. 
ual $\alpha$-Gal A activity or late-onset cardiomyopathy without systemic manifestations has been reported. ${ }^{2-5)}$

Fabry's disease can be diagnosed enzymatically in affected hemizygous males by a deficiency in $\alpha$-Gal A activity in plasma and leukocytes. In contrast, the identification of heterozygous females is often inconclusive due to the random X-chromosomal inactivation. However, the locus for $\alpha$-Gal A is assigned to the long arm of the $\mathrm{X}$ chromosome within band Xq 22. The entire 12-kb $\alpha$-Gal A gene, which contains seven exons, is completely sequenced. Thus, genetic analysis is essential for identifying genotype/phenotype correlations and permitting precise heterozygote detection. Moreover, early diagnosis is important and needed since recent clinical trials showed the safety and efficacy of human recombinant $\alpha$-Gal A. ${ }^{6}$

We describe a female patient with Fabry's disease mimicking hypertrophic cardiomyopathy, confirming a missense mutation in the $\alpha$-Gal A gene for precise diagnosis in a heterozygous state.

\section{Case Report}

A 56-year-old Japanese woman presented at our clinic with dyspnea and bradycardia. On physical examination, her blood pressure was $120 / 76 \mathrm{mmHg}$ with an irregular pulse rate of 66 beats/min. No heart murmur was heard. Angiokeratoma, acroparesthesis, and hypohydrosis were observed for the first time but corneal opacity and abnormal neurological findings were not found. An electrocardiogram demonstrated atrial fibrillation. Holter ECG recording showed an idioventricular rhythm (34 beats/min) at midnight. An echocardiogram indicated left ventricular hypertrophy (the thicknesses of the interventricular septum and left ventricular posterior wall were $15 \mathrm{~mm}$ and $7 \mathrm{~mm}$ ), dilatation (end-diastolic and end-systolic dimensions, $60 \mathrm{~mm}$ and $48 \mathrm{~mm}$ ), and poor systolic function (left ventricular ejection fraction, $30 \%)$. On laboratory examination, proteinuria was detected (Table). Total bilirubin $(2.7 \mathrm{mg} / \mathrm{dL})$ and LDH $(719 \mathrm{IU} / \mathrm{L})$ levels were high and the platelet count $\left(13.4 \times 10^{4} / \mu \mathrm{L}\right)$ was low. Consequently, she was tentatively diagnosed as having a dilated form of hypertrophic cardiomyopathy in conjunction with angiokeratoma and proteinuria.

For the differentiation of Fabry's disease from hypertrophic cardiomyopathy, informed consent was obtained from the patient before the $\alpha$-Gal A activity and gene analyses. $\alpha$-Gal A activity was analyzed in the homogenates of peripheral lymphocytes with the substrate of $5 \mathrm{mM} 4$-methylumbelliferyl- $\alpha$-galactosidase (Sigma-Aldrich, Tokyo) at pH 4.5 by the method of Suzuki. ${ }^{7)}$ Genomic DNA was extracted from peripheral lymphocytes by the standard method ${ }^{8)}$ and each exon was amplified by polymerase chain reaction according to a previoius 
Table. Laboratory Data

\begin{tabular}{|c|c|c|}
\hline & & Normal range \\
\hline $\mathrm{WBC}\left(\times 10^{2} / \mu \mathrm{L}\right)$ & 42 & $43-80$ \\
\hline $\mathrm{RBC}\left(\times 10^{4} / \mu \mathrm{L}\right)$ & 451 & $395-465$ \\
\hline $\mathrm{Hgb}(\mathrm{g} / \mathrm{dL})$ & 14.5 & $11.3-14.9$ \\
\hline $\operatorname{Het}(\%)$ & 42.7 & $36.0-47.0$ \\
\hline $\mathrm{PlC}\left(\times 10^{4} / \mu \mathrm{L}\right)$ & 13.4 & $18-34$ \\
\hline $\mathrm{TP}(\mathrm{g} / \mathrm{dL})$ & 7.6 & $6.5-8.5$ \\
\hline Alb (g/dL) & 4.1 & $3.5-5.0$ \\
\hline T-Bil (mg/dL) & 2.7 & $0.2-1.0$ \\
\hline Amylase (IU/L) & 12 & $40-200$ \\
\hline $\operatorname{AST}(\mathrm{IU} / \mathrm{L})$ & 54 & $12-40$ \\
\hline ALT (IU/L) & 20 & $10-45$ \\
\hline ALP (IU/L) & 193 & $80-230$ \\
\hline $\mathrm{ChE}(\mathrm{IU} / \mathrm{L})$ & 416 & $350-750$ \\
\hline LDH (IU/L) & 719 & $250-500$ \\
\hline CK (IU/L) & 126 & $30-140$ \\
\hline BUN (mg/dL) & 21 & $7.0-18$ \\
\hline Cre $(\mathrm{mg} / \mathrm{dL})$ & 0.63 & $0.4-0.9$ \\
\hline $\mathrm{Na}(\mathrm{mEq} / \mathrm{L})$ & 141 & $137-146$ \\
\hline $\mathrm{K}(\mathrm{mEq} / \mathrm{L})$ & 5.0 & $3.8-5.1$ \\
\hline $\mathrm{Cl}(\mathrm{mEq} / \mathrm{L})$ & 103 & $98-108$ \\
\hline $\mathrm{FBS}(\mathrm{mg} / \mathrm{dL})$ & 106 & $70-105$ \\
\hline \multicolumn{3}{|l|}{ Urine } \\
\hline $\mathrm{pH}$ & 6.0 & $4.5-7.0$ \\
\hline Glucose (mg/dL) & 0 & $0-30$ \\
\hline Protein $(\mathrm{mg} / \mathrm{dL})$ & 30 & $0-20$ \\
\hline Bilirubin $(\mathrm{mg} / \mathrm{dL})$ & 0 & 0 \\
\hline Urobilinogen (mg/dL) & 0.1 & $0.2-2.0$ \\
\hline
\end{tabular}

method, ${ }^{9)}$ with some modifications. PCR products were sequenced by a direct sequencing method using a capillary sequencer (ABI PRISM 310 Genetic Analyzer, Perkin Elmer Japan Co./ABI Inc., Chiba, Japan) with a Rhodamin Terminater Cycle Sequencing Kit from the same company.

$\alpha$-Gal A activity was considerably low $(5.5 \mathrm{nmol} / \mathrm{mg} / \mathrm{h})$ compared to the normal control $(n=26)$ value of $18.2 \pm 5.9 \mathrm{nmol} / \mathrm{mg} / \mathrm{h}$. In the molecular analysis of the $\alpha$-Gal A gene, an amino acid substitution of leucine (CTG) to proline (CG) at codon 19 was found to result in a heterozygous state. This was a novel mutation and was located almost immediately downstream to the signal peptide sequence (codon 1-17).

Her 29-year-old son was apparently healthy without any complaints but had angiokeratoma, acroparesthesis, and hypohydrosis. He had a normal ECG. Echocardiographic studies showed normal left ventricular function without hypertrophy. On laboratory examination, proteinuria was detected but the glomerular filtration rate was $93 \mathrm{~mL} / \mathrm{h}$. $\alpha$-Gal A activity was considerably below nor- 


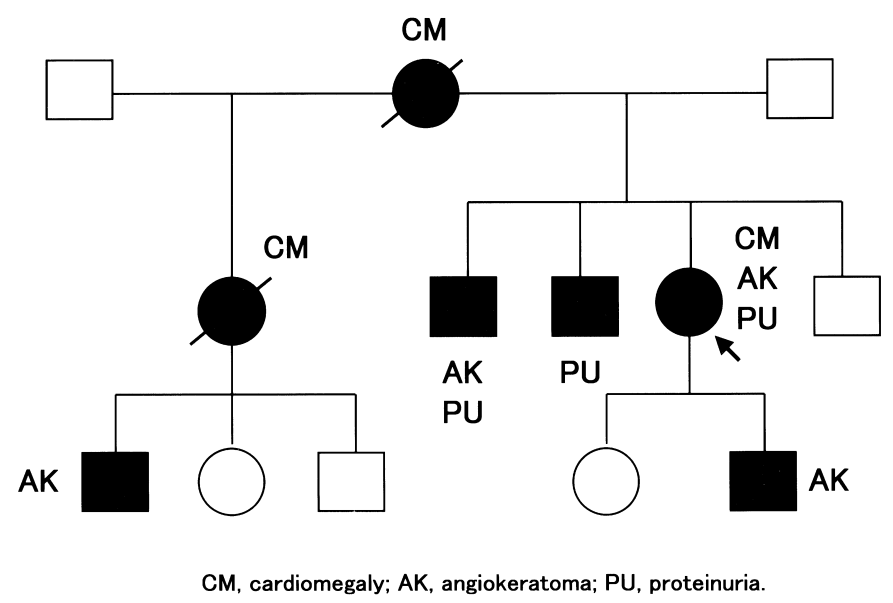

Figure. Pedigree of the present family. Blackened symbols denote individuals with symptoms related to Fabry's disease.

$\mathrm{CM}=$ cardiomegaly $; \mathrm{AK}=$ angiokeratoma; $\mathrm{PU}=$ proteinuria.

mal $(2.6 \mathrm{nmol} / \mathrm{mg} / \mathrm{h})$ indicating a hemizygote. In the molecular analysis of the $\alpha$ Gal A gene, the same mutation was found as in his mother. Meanwhile, her daughter had normal $\alpha$-Gal A activity $(19.0 \mathrm{nmol} / \mathrm{mg} / \mathrm{h})$ and no gene mutation, consistent with the results of enzyme analysis. The Figure shows this family pedigree.

\section{DISCUSSION}

Precise diagnosis may be delayed or missed since the cardiac manifestation of Fabry's disease often mimics hypertrophic cardiomyopathy. ${ }^{10)}$ At first, she was tentatively suspected of having hypertrophic cardiomyopathy in the echocardiographic examination. However, the angiokeratoma and proteinuria suggested to us other causes of hypertrophy rather than hypertrophic cardiomyopathy. Therefore, $\alpha$-Gal A activity was measured and the final diagnosis was confirmed by genetic analysis.

Consequently, we found a Fabry heterozygote with the classic form, identifying a novel missense mutation (L19P) with amino acid substitution in the $\alpha$-Gal A gene. This was presumed to be a disease-causing mutation and to cause conformational change in the $\alpha$-Gal A gene.

Enzymatic activity is useful for diagnosing Fabry's disease in hemizygous males, differentiating it from other causes of cardiac hypertrophy. However, this is often inconclusive for the identification of heterozygous females. As a result, it 
is important to analyze mutations in Fabry's disease since the detection of these mutations provides a precise diagnosis of the heterozygous carriers of the $\mathrm{X}$ linked recessive disorder and molecular prenatal diagnosis.

Fabry's disease may not be rare in cardiac hypertrophy. When 230 or 153 male patients with cardiac hypertrophy were screened, 7 or 6 cases $(3 \%$ or $4 \%$ ) exhibited Fabry's disease as a cardiac variant, respectively. ${ }^{4,5}$ Cardiac involvement with hypertrophy and valvular abnormalities is also common in heterozygous females. ${ }^{11)}$

In summary, we conclude that it is important to consider Fabry's disease in the differential diagnosis of cardiac hypertrophy since the disease is treatable and the enzyme replacement therapy can clear the capillary endothelial accumulation of glycosphingolipids in the kidneys, heart, and skin. ${ }^{6,10)}$ Therefore, it is necessary to measure $\alpha$-Gal A activity in all patients suspected of having Fabry's disease and to analyze gene mutations in heterozygotes as well as to confirm the intralysosomal deposition of glycosphingolipids in endomyocardial biopsy specimens.

\section{REFERENCES}

1. Desnick RJ, Ioannou YA, Eng CM. $\alpha$-Galactosidase A Deficiency. Fabry's disease. In: Scriver CR, Beaudet AL, Sly WS, Valle D, editors. The Metabolic and Molecular Basis of Inherited Diseases, 8th ed. McGraw-Hill, New York, 2001; 3733-74.

2. Sakuraba H, Oshima A, Fukuhara Y, et al. Identification of point mutations in the $\alpha$-galactosidase A gene in classical and atypical hemizygotes with Fabry's disease. Am J Hum Genet 1990; 47: 784-9.

3. von Scheidt W, Eng C, Fitzmaurice T, et al. An atypical variant of Fabry's disease with manifestations confined to the myocardium. N Engl J Med 1991; 324: 395-9.

4. Nakao S, Takenaka T, Maeda M, et al. An atypical variant of Fabry's disease in men with left ventricular hypertrophy. N Engl J Med 1995; 333: 288-93.

5. Sachdev B, Takenaka T, Teraguchi H, et al. Prevalence of Anderson-Fabry disease in male patients with late onset hypertrophic cardiomyopathy. Circulation 2002; 105: 1407-11.

6. Eng CM, Guffon N, Wilcox WR, et al. Safety and efficacy of recombinant human $\alpha$-galactosidase A replacement therapy in Fabry's disease. N Engl J Med 2001; 345: 9-16.

7. Suzuki K. Enzymatic diagnosis of sphingolipidoses. Meth Enzymol 1987; 138: 727-62.

8. Sambrook J, Fritsch EF, Maniatis T. Molecular Cloning: a Laboratory Manual, 2nd ed. Cold Spring Harbor Laboratory, Cold Spring Harbor, New York, 1989.

9. Kornreich R, Desnick RJ. Fabry's disease: Detection of gene rearrangements in the human $\alpha$-galactosidase A gene by multiplex PCR amplification. Hum Mutat 1993; 2: 108-11.

10. Desnick RJ, Brady R, Barranger J, et al. Fabry disease, an under-recognized multisystemic disorder: expert recommendation for diagnosis, management, and enzyme replacement therapy. Ann Int Med 2003; 138: 338-46.

11. Kampmann C, Baehner F, Whybra C, et al. Cardiac manifestations of Anderson-Fabry disease in heterozygous females. J Amer Coll Cardiol 2002; 40: 1668-74. 